\title{
DISTRIBUIÇÃO NATURAL DE ESPÉCIES ARBÓREAS E AVALIAÇÃO DOS CARÁTERES SILVICULTURAIS PARA FINS DE INTEGRAR PROGRAMA DE CONSERVAÇÃO GENÉTICA IN SITU
}

\author{
Hemerson Fernandes Calgaro ${ }^{1}$, José Cambuim² ${ }^{2}$, Alexandre Marques da Silva ${ }^{3}$, Angelica \\ Christina Melo Nunes ${ }^{4}$, Salatiér Buzetti ${ }^{5}$, Marcela Aparecida de Moraes ${ }^{6}$, Mario Luiz \\ Teixeira de Moraes $^{7}$
}

\footnotetext{
${ }^{1}$ Assistente Agropecuário da Secretaria de Agricultura e Abastecimento do Estado de São Paulo, Lins (SP).

2 Administrador, Auxiliar Agropecuário na Fazenda de Ensino, Pesquisa e Extensão - Doutorando em Agronomia na UNESP Campus de Ilha Solteira (SP).

${ }^{3}$ Geógrafo, Técnico Agropecuário do Departamento de Fitotecnia, Tecnologia de Alimentos e Sócio Economia - Doutorando em Agronomia da UNESP Campus de Ilha Solteira (SP).

${ }^{4}$ Graduanda do curso de Engenharia Ambiental da UNILINS, Lins (SP).

${ }^{5}$ Prof. Titular do Departamento de Fitossanidade, Engenharia Rural e Solos da UNESP Campus de Ilha Solteira (SP).

${ }^{6}$ Doutorando em Agronomia na UNESP Campus de Ilha Solteira (SP).

${ }^{7}$ Prof. Titular do Departamento de Fitotecnia, Tecnologia de Alimentos e Sócio Economia da UNESP Campus de Ilha Solteira (SP).
}

RESUMO: Os caráteres silviculturais passaram a ter importância no entendimento do processo sucessional e de distribuição das espécies arbóreas e no planejamento de recomposição da paisagem. O objetivo do trabalho foi avaliar os caráteres silviculturais e a distribuição espacial de espécies arbóreas, em áreas com diferentes níveis de antropização para integrar programa de conservação genética in situ. $\mathrm{O}$ trabalho foi desenvolvido em área da Fazenda Experimental de Pesquisa e Extensão da UNESP de Ilha Solteira, município de Selvíria-MS. Por meio de transecto foram demarcadas 64 parcelas equidistantes de $50 \mathrm{~m}$ com dimensões de 10 x 10 m, sendo: 29 parcelas em área altamente antropizada; cinco em área medianamente antropizada; 15 em área pouco antropizada (APA); seis na mata ciliar do córrego da Véstia e nove na Reserva legal. Avaliou-se altura, diâmetro a altura do peito (DAP), forma, e a autocorrelação espacial. Conclui-se que: o nível de antropização e conservação das áreas influenciam a ocorrência natural, diversidade de espécies e desenvolvimento dos indivíduos arbóreos; a altura, DAP e forma são bons indicadores para avaliar o crescimento das espécies arbóreas; a APA e a Reserva legal apresentam maior ocorrência natural, número de indivíduos e número de espécies; na Mata ciliar os valores de área basal, altura e forma são superiores. Por não apresentar estruturação em nenhuma das classes de distâncias, pertinente ao estudo de distribuição espacial, a espécie mais indicada para integrar a um programa de conservação genética in situ é Astronium fraxinifolium.

Palavras-chave: Autocorrelação espacial. Espécies arbóreas. Área degradada. Conservação genética.

\section{NATURAL DISTRIBUTION OF TREE SPECIES AND EVALUATION OF SILVICULTURAL CHARACTERS FORTHE PURPOSE OF INTEGRATING}

Cultura Agronômica, Ilha Solteira, v.24, n.4, p.301-320, 2015 


\section{GENETIC CONSERVATION PROGRAM IN SITU}

ABSTRACT: The silvicultural characters have gained importance in understanding the successional process and distribution of trees species and restoration of landscape planning. The objective of this study was to evaluate the silvicultural characters and spatial distribution of tree species in areas with different levels of anthropogenic program to integrate in situ genetic conservation. The work was conducted at the Experimental Farm Research and Extension of Single Island UNESP, municipality of Selviria - MS. Through transect were marked 64 plots of 50 m equidistant with dimensions of 10 x $10 \mathrm{~m}$. Where: 29 plots in the highly disturbed, moderately disturbed area in five, 15 in an area slightly disturbed (APA), six in the riparian stream of Vestia and nine in the legal reserve. We evaluated the silvicultural characters such as height, diameter at breast height (DBH), shape, and spatial autocorrelation. We evaluated the silvicultural characters such as height, diameter at breast height $(\mathrm{DBH})$, shape, and spatial autocorrelation. Based on the results concluded that: the level of anthropogenic influence areas and conservation of the natural occurrence, species diversity and development of the individual trees, the height, DBH and shape are good indicators to assess the growth of tree species, the APA Legal reserve and are more natural occurrence, number of individuals and number of species, riparian forest in the values of basal area, height and shape are higher, based on the study of spatial distribution of the species most suitable to integrate a program of genetic conservation Astronium fraxinifolium in situ is not present in any structure of the classes of distances.

Key words: Spatial autocorrelation. Tree species. Degraded areas. Conservation genetics.

\section{INTRODUÇÃO}

A redução de áreas ocupadas por vegetação nativa tem aumentado a perda da biodiversidade e o empobrecimento dos recursos genéticos (MYERS et al., 2000). A restauração de áreas degradadas representa uma atividade básica para a conservação in situ, refazendo comunidades e estabelecendo corredores entre fragmentos vegetacionais (REIS et $a l .$, 2003). O material genético utilizado na restauração deve representar geneticamente o ambiente em que a área está inclusa. Conforme Kageyama (2003), o ideal é coletar sementes na própria área ou em áreas próximas de vegetação remanescentes. A conservação in situ de recursos genéticos é considerada a forma mais efetiva, quando toda comunidade de espécies está sendo o objetivo da conservação (BARBOSA et al., 2008).

A conservação in situ é importante por permitir que as espécies continuem seus processos evolutivos, gerando novos genótipos, particularmente, em resposta às mudanças ambientais e para conferir resistência a novos patógenos; bem como para que a seleção ocorra de maneira contínua. O benefício dessa prática está na conservação da biodiversidade de todo ecossistema, do que apenas amostras de germoplasmas de uma espécie. A desvantagem da conservação in situ é que o germoplasma não poder ser utilizado de forma eficiente, por não se encontrar disponível para exploração rápida (HAYAWARD; 
HAMILTON, 1997). Simon (2010), ainda realça dificuldades na conservação genética in situ como o baixo nível de controle e conhecimento sobre o que se está conservando, risco de declínio da população causado por patógenos, catástrofes naturais, incêndios e desmatamento e também pela limitação da diversidade genética que pode ser preservada por espécie. Por outro lado, o mesmo autor considera a conservação de recursos genéticos, uma estratégia para espécies de importância econômica.

Segundo Nascimento et al. (1999) o conhecimento da distribuição espacial das espécies arbóreas é de fundamental importância como base para o planejamento do manejo adequado e aproveitamento racional dos recursos florestais. A distribuição espacial dos indivíduos arbóreos de uma floresta é uma das principais características da estrutura populacional das espécies. Determina a forma de ocorrência dos indivíduos de uma espécie na floresta, sendo influenciada pelo comportamento ecológico dos agentes de fluxo gênico envolvidos, tais como: a dispersão do pólen, de sementes e a regeneração de plântulas.

O objetivo do trabalho foi avaliar os caráteres silviculturais e a distribuição espacial de espécies arbóreas, em áreas com diferentes níveis de antropização, para integrar programa de conservação genética in situ.

\section{MATERIAL E MÉTODOS}

O presente trabalho foi instalado e desenvolvido na Fazenda Experimental de Pesquisa e Extensão - FEPE, da Faculdade de Engenharia - Campus de Ilha Solteira - UNESP, localizada no município de Selvíria (MS). As coordenadas geográficas do local são 51'24'17,02" W de longitude e 20²1'48,30" S de latitude, Datum SAD 69, média anual de precipitação de $1.684 \mathrm{~mm}$ e $327 \mathrm{~m}$ de altitude. A temperatura média anual é de $24,5^{\circ} \mathrm{C}$, sendo janeiro e fevereiro os meses mais quentes (média de $26^{\circ} \mathrm{C}$ ) e junho e julho os mais frios (média de $21^{\circ} \mathrm{C}$ ). A umidade relativa média é de 72,1\% (UNESP, 2010) e o clima predominante na região é do tipo Aw (KOPPEN, 1948).

A área de estudo está no Planalto da Bacia Sedimentar do Paraná e apresenta declives muito suaves, relevo plano a suavemente ondulado (ALVES; SOUZA, 2008). O solo de maior ocorrência no local foi classificado por Demattê (1980), que efetuou o Levantamento Detalhado dos Solos do Campus Experimental da Faculdade de Engenharia - FE/UNESP Ilha Solteira e dessa forma, a presente pesquisa foi realizada no seguinte solo, cuja adequação da nomenclatura foi realizada por Carvalho $(2009)^{1}$ consubstanciada ao Sistema Brasileiro de Classificação do Solo (EMBRAPA, 2006), sendo um Latossolo Vermelho Distrófico típico textura média, "A" moderado, hipodistrófico, álico, caulinítico, hipoférrico, muito profundo, fortemente ácido. A sua fração argila é de baixa atividade e denominada essencialmente pela gibsita e caulinita (SILVA et al., 2005).

Para avaliar a distribuição de espécies arbóreas nas áreas com diferentes níveis de perturbação antrópica as áreas em questão, foram divididas em 64 parcelas que,

\footnotetext{
1 Morel Passos de Carvalho. Faculdade de Engenharia - UNESP - Campus de Ilha Solteira. 2009.
} Comunicação pessoal.

Cultura Agronômica, Ilha Solteira, v.24, n.4, p.301-320, 2015 
posteriormente, foram analisadas pelo método de estruturação espacial; mensurada por meio do Índice de Moran.

Os índices de Moran descrevem os padrões de autocorrelação espacial ao longo de toda superfície de variação. Assim, eles só podem ser calculados para grupos de subpopulações afastadas entre si por uma dada distância, ou intervalo (h). Portanto, a matriz de distâncias geográficas $\mathrm{W}$, com n(n-1)/2 observações, pode ser dividida em diversas matrizes de conectividade $\mathrm{Wk}$, cada uma delas ligando sucessiva e exclusivamente pares de subpopulações afastadas por um intervalo $\mathrm{h}$ crescente, para cada uma das $\mathrm{k}$ classes de distâncias. Quando os índices de Moran são calculados, para uma mesma variável, utilizando essas diversas matrizes Wk e contrastadas com esse aumento no intervalo na distância geográfica, obtém-se um correlograma espacial (SOKAL; ODEN, 1978a,b).

\subsection{Demarcação das parcelas}

Foram demarcadas 64 parcelas, com estaca no centro geométrico e georeferenciadas com um receptor GPS (Global Positioning System) ${ }^{2}$. Seguiu-se um transecto iniciando na mata da RL da FEPE, atravessou a área degradada até a mata ciliar do córrego da Véstia, totalizando uma extensão aproximada de 3.500 m (Figura 1). Sendo que, nove parcelas foram demarcadas na mata da RL; seis parcelas na Mata ciliar do córrego da Véstia e 49 parcelas na área degrada. Destas últimas, dividiu-se como forma a estratificar o nível de antropização, em três áreas distintas, ou seja, 29 parcelas em área considerada altamente antropizada e sem gramíneas (AAA); cinco parcelas em área considerada medianamente antropizada e com gramíneas (AMA) e 15 parcelas em área considerada pouco antropizada, sem gramíneas e revegetada espontaneamente com indivíduos arbóreos, em estágio avançado de regeneração (APA).

Cada parcela possui área igual a $100 \mathrm{~m}^{2}(10$ x $10 \mathrm{~m})$, mantendo equidistâcia de $50 \mathrm{~m}$, totalizando $6.400 \mathrm{~m}^{2}(0,64 \mathrm{ha})$ (Figura 10). A distribuição das cinco áreas ficou da seguinte forma: (1) $2.900 \mathrm{~m}^{2}$ (0,29 ha); (2) $500 \mathrm{~m}^{2}$ (0,05 ha); (3) $1.500 \mathrm{~m}^{2}$ (0,15 ha); (4) $600 \mathrm{~m}^{2}$ (0,06 ha) e (5) $900 \mathrm{~m}^{2}(0,09 \mathrm{ha})$.

A variação do número de parcelas por área estudada é devido às estas possuírem dimensões diversas e ainda, pela utilização de transecto para servir de norteador na coleta de dados, não foi possível obter um número igualitário ou mesmo semelhante entre as áreas.

${ }^{2}$ Etrex, modelo Venture.

Cultura Agronômica, Ilha Solteira, v.24, n.4, p.301-320, 2015 


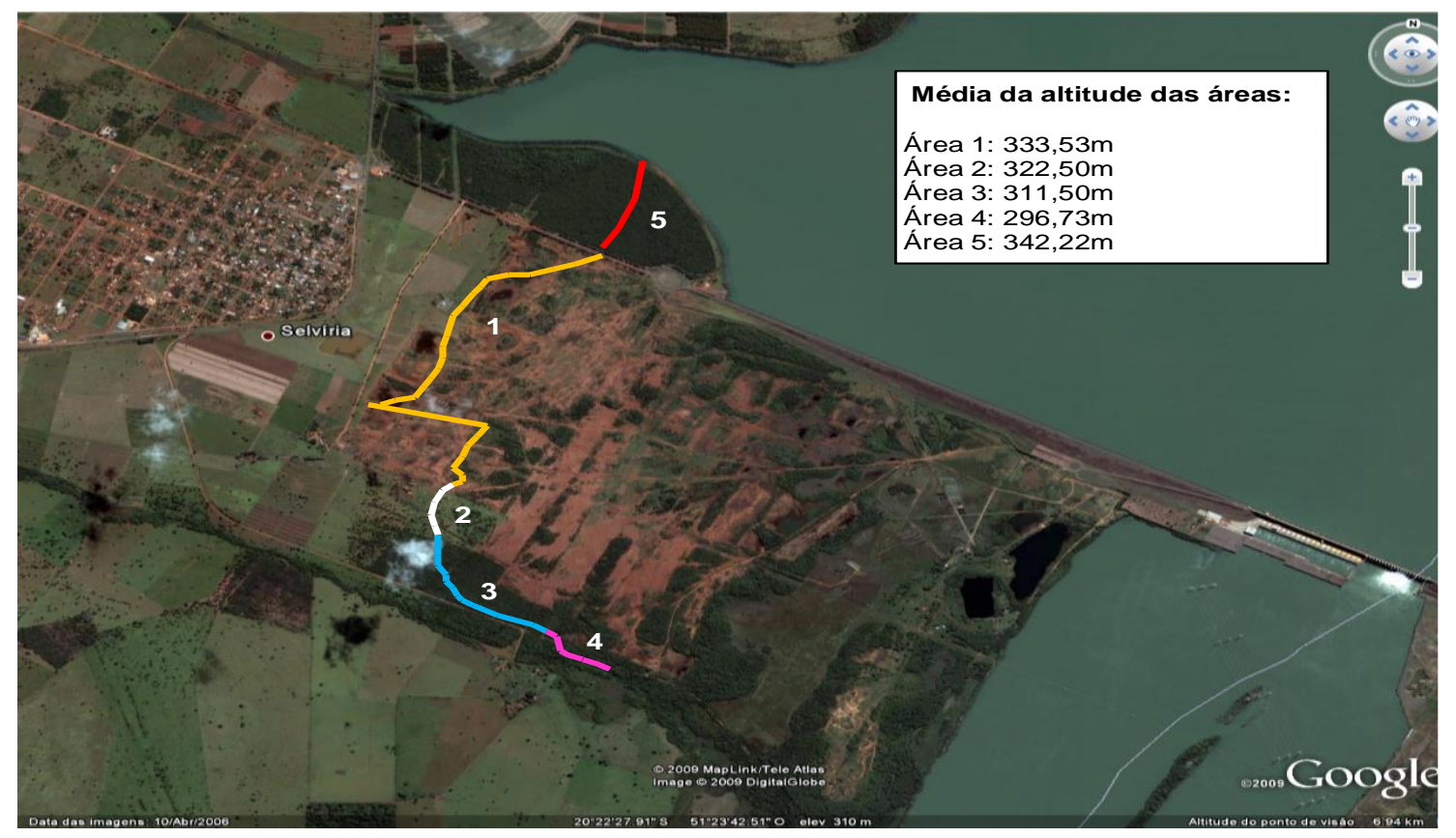

Figura 1. Imagem aérea datada de 2006, obtida pelo software Google Earth, com identificação do transecto, onde foram alocadas as parcelas, em área da FEPE-UNESP, município de Selvíria-MS. Áreas: 1) cor amarela: Área altamente antropizada (AAA); 2) cor branca: Área medianamente antropizada (AMA); 3) cor azul: Área pouco antropizada (APA); 4) cor rosa: Mata ciliar; 5) cor alaranjado: Reserva legal (RL). Fonte: Google Earth Software.

Fonte da imagem: Software Google Earth.

\subsection{Histórico das Áreas Avaliadas}

Originalmente, a área apresentava como cobertura vegetal o Cerrado stricto sensu, porém, no final da década de 60, com a construção da Usina Hidrelétrica de Ilha Solteira, houve desmatamento em grande parte da mesma, o que provocou a redução do número de indivíduos arbóreos e consequentemente de toda biodiversidade, sendo o solo utilizado nas obras da fundação da barragem, tomando esta área, a denominação de "área de empréstimo". No entorno da Usina Hidrelétrica de Ilha Solteira, as "áreas de empréstimo" podem ser consideradas áreas degradadas, uma vez que delas foram retirados os horizontes superficiais do solo, são áreas com intensos sinais de degradação que, apesar de não sofrerem intervenções semelhantes há mais de 30 anos, apresentam insignificante regeneração natural (RODRIGUES et al., 2007).

\subsection{Caracterização das áreas avaliadas}

\subsection{1 Área altamente antropizada (AAA): 1}

Caracterizada pelo subsolo exposto desde 1969 (ALVES; SOUZA, 2008), pouca vegetação, tanto rasteira como arbórea e evidentes processos erosivos. Em se tratando da vegetação rasteira, evidenciam-se plantas típicas de solos com pH ácido e degradados. Observou-se presença de gado, porém, sem nenhuma prática de manejo.

Árvores com altura média de 5,6 m, escassos agrupamentos de indivíduos arbóreos, Cultura Agronômica, Ilha Solteira, v.24, n.4, p.301-320, 2015 
não sendo possível a formação de dossel. Há pasto (gramíneas) no entorno, o curso do rio e a continuação da área alagada da hidrelétrica. Possui baixa diversidade e quantidade de espécies arbóreas.

Neste local, as parcelas demarcadas iniciam na de número 1 e vão até a 29 e locadas em áreas nas quais foram removidos, em grande parte, até $12 \mathrm{~m}$ de profundidade de solo, utilizados na construção do aterro da barragem. Nestes locais, a altitude média é de 333,53 m.

\subsection{2 Área medianamente antropizada (AMA): 2}

Área caracterizada pela presença homogênea de pasto (gramíneas), sob manejo de pastejo extensivo, entretanto, com ausência de práticas conservacionista de solo.

Árvores com altura média e formação de dossel a 7,7 m, presença de alguns agrupamentos de indivíduos arbóreos. Há no entorno pasto com gramínea e a área anterior (AAA). Como há a prática do manejo de pastejo de semoventes, há a interferência destes na regeneração vegetal.

Neste local as parcelas demarcadas iniciam na de número 30 seguindo até a 34 e estão localizadas numa altitude média de $322,50 \mathrm{~m}$. Neste trecho do transecto, foi removido no período da construção da hidrelétrica, menos solo quando comparado ao trecho 1 (AAA), estimando-se a retirada em torno de $6 \mathrm{~m}$ de profundidade.

\subsection{3 Área pouco antropizada (APA): 3}

Área caracterizada por estar revegetada com indivíduos arbóreos nativos, dossel semifechado e fechado a uma altura média de $8,3 \mathrm{~m}$. Com pouca vegetação rasteira, mas com grande número de indivíduos de espécies arbóreas, regenerados provavelmente pelo banco de sementes e a dispersão de estruturas reprodutivas via endozoocórica, anemocórica, autocórica entre outros.

As parcelas demarcadas iniciam na de número 35 seguindo até a 49 e situam-se a uma altitude média de $311,50 \mathrm{~m}$. Neste trecho do transecto o solo foi removido à profundidade estimada de $4 \mathrm{~m}$. No seu entorno há a área anterior (AMA) e a mata ciliar do córrego da Véstia. Proporcionalmente às outras áreas estudadas, foi a que apresentou maior diversidade de espécies vegetais.

\subsubsection{Mata ciliar: 4}

Esta área caracteriza-se pela presença de serapilheira, lianas e epífitas, ausência de gramíneas em função do dossel fechado, o qual está numa altura de 11,6 m, árvores altas e grande número de vegetação regenerante, formando sub-bosque.

Há também grande ocorrência de cipós e lianas. A Mata ciliar limita-se aos $30 \mathrm{~m}$ previstos na legislação e possui características peculiares, pois faz divisa de um lado por estrada não pavimentada e do outro com área de pasto de propriedade particular. Este cenário causa um efeito de borda, o que acaba interferindo no processo sucessional das espécies. Há ainda, o relato de que até meados da década de 90, servia como área de pastejo para o gado da FEPE, inclusive com trânsito de trator com roçadeira de arrasto. 
Neste local, as parcelas demarcadas iniciam na de número 50 seguindo até a 55 e encontram-se numa altitude média de 296,73 m.

\subsubsection{Reserva legal: 5}

Local com espessa camada de serapilheira, dossel fechado, o qual está numa altura média de 8,6 m, baixa infestação de plantas daninhas e presença de cipós e lianas nas parcelas localizadas na zona periférica (borda). Representa como era, teoricamente, o Cerrado, entretanto, atualmente, podem ser observadas espécies de floresta semidecídua, sinalizando a ocorrência de um ecótono, como constatado por Aragão (2008). Verifica-se a presença de grande número de indivíduos arbóreos mensurados e alta diversidade, quando comprado às demais áreas.

A vegetação é caracterizada como primária (natural), pois o inventário temporal, obtido por funcionários antigos da Fazenda de Ensino, Pesquisa e Extensão da Faculdade de Engenharia - FEPE/UNESP, Campus de Ilha Solteira e de moradores circunvizinhos, relatam que a área nunca foi objeto de corte raso da vegetação, sendo mantida pela Universidade como RL, mesmo antes de sua averbação em cartório.

Esta área recebe influência causada pela elevação do nível de água do reservatório, uma vez que, esta área passou a ser ou desempenhar uma função de mata ciliar. As parcelas contidas nesta área encontram-se numa altitude média de 342,22 m.

Neste local, as parcelas demarcadas iniciam na de número 56 finalizando na de número 64.

\subsection{Características silviculturais}

Os caráteres silviculturais avaliados foram altura total da planta (ALT) em metros, utilizando aparelho hipsométrico ${ }^{3}$; diâmetro a altura do peito (DAP) em centímetros, obtido pela expressão:

$$
D A P=\frac{P A P}{\pi}
$$

Mensurou-se o perímetro da altura do peito (PAP) a 1,30 m do solo, com a utilização de fita métrica, devido às irregularidades presentes nos troncos dos indivíduos arbóreos, propondo-se a minimizar estas desuniformidades.

Por se tratar de espécies nativas em condições diferentes de desenvolvimento, atribuiu-se a metodologia própria, elaborada e aplicada por Guerra (2008), para avaliação do fuste das árvores mensuradas. Desta maneira, estabeleceram-se notas, para fuste a 2,20 m, onde a forma do tronco (FOR) variou numa escala de um a cinco, tanto para bifurcação (B) como para retidão $(\mathrm{R})$, sendo que a nota final foi dada, utilizando-se da expressão:

$$
F O R=\frac{(B+R)}{2}
$$

${ }^{3}$ VERTEX III e Transponder T3.

Cultura Agronômica, Ilha Solteira, v.24, n.4, p.301-320, 2015 


\subsection{Ocorrência, identificação e classificação das espécies arbóreas}

Todas as espécies arbóreas presentes nas 64 parcelas demarcadas, desde o estágio de plântula até adulto, foram identificadas. Avaliou-se ainda as de diâmetro a altura do peito igual ou superior a $0,06 \mathrm{~m}$, sendo classificadas por bioma a que pertenciam para estudo de distribuição de ocorrência. Justifica-se a medida praticada do DAP, uma vez que, a partir deste valor é que se pode mensurar economicamente, quando o interesse é madeireiro.

A classificação das espécies seguiu critérios da APG II (SOUZA; LORENZI, 2005). A identificação das espécies arbóreas em condições de campo foi realizada com base em: Almeida et al. (1998); Lorenzi (2002ab); Durigan et al. (2004); Silva Junior et al. (2005); Carvalho (2006); Ramos et al. (2008) e Cambuim.

As espécies de ocorrência natural foram classificadas segundo Kageyama e Gandara (1993), em: Muito Comuns (MC) (20 - 100 ind ha' ${ }^{-1}$, Comuns (C) (1 - 20 ind ha ${ }^{-1}$ ) e Raras $\left(0,1-1\right.$ ind ha $\left.^{-1}\right)$.

\subsection{Estruturação espacial}

O padrão espacial relacionado a altura e DAP foi avaliado através dos procedimentos de autocorrelação espacial (SOKAL; ODEN 1978a,b). A autocorrelação espacial em caráteres genéticos tem sido usualmente mensurada através do Índice de Moran (1950), dado por:

$$
I=\left(\frac{n}{w}\right)\left[\frac{\sum_{i} \sum_{j}\left(p_{i}-\bar{p}\right)\left(p_{j}-\bar{p}\right) w_{i j}}{\sum_{j}\left(p_{i}-\bar{p}\right)^{2}}\right]
$$

Em que: n é o número de populações ou indivíduos locais analisados; $\mathrm{p}_{\mathrm{i}} \mathrm{p}_{\mathrm{j}}$ são os valores dos caráteres morfológicos nas populações ou famílias i e j, $p$ é o valor médio de $\mathrm{p}$ e $\mathrm{W}_{\mathrm{ij}}$ é o elemento da matriz quadrada e simétrica $\mathrm{W}$, com dimensões $\mathrm{n} \times \mathrm{n}$, que expressa a relação espacial entre as n população ou famílias locais e cuja soma, ao longo de i e j, é igual ao valor de w. O valor de I é estandartizado, de modo que seus valores são independentes da variância de $\mathrm{p}$, sendo função apenas de forma da superfície formada por $\mathrm{p}$ sobre o espaço.

O índice de Moran varia entre -1,0 a 1,0, sendo seus máximos para autocorrelações negativas e positivas, respectivamente, sendo assim sua interpretação é análoga à de um coeficiente de correlação, como o de Pearson.

Os índices de Moran descrevem os padrões de autocorrelação espacial ao longo de toda superfície de variação. Assim, eles só podem ser calculados para grupos de subpopulações afastadas entre si por uma dada distância, ou intervalo (h). Portanto, a matriz de distâncias geográficas $\mathrm{W}$, com $\mathrm{n}(\mathrm{n}-1) / 2$ observações, pode ser dividida em diversas matrizes de conectividade $\mathrm{W}_{\mathrm{k}}$, cada uma delas ligando sucessiva e exclusivamente pares de subpopulações afastadas por um intervalo $\mathrm{h}$ crescente, para cada uma das $\mathrm{k}$ classes de distâncias. Quando os índices de Moran são calculados, para uma mesma variável, utilizando essas diversas matrizes $\mathrm{W}_{\mathrm{k}}$ e contrastadas com esse aumento no intervalo na 
distância geográfica, obtém-se um correlograma espacial (SOKAL; ODEN 1978a,b). Deste modo, é possível descrever o quanto as subpopulações, a uma dada distância, são similares para variável analisada e como essa similaridade muda com o aumento das distâncias geográficas. Por isso, a matriz W deve ser bem definida em uma análise de autocorrelação, pois essa matriz pode conter uma simples medida de conectividade, ou vizinhança, entre populações. Nessa matriz o valor $\mathrm{w}_{\mathrm{ij}}=1,0$ indica que as localidades $\mathrm{i}$ e $\mathrm{j}$ estão conectadas espacialmente e valor zero em caso contrário. Assim, para construir-se um correlograma espacial é necessário avaliar como as populações ou indivíduos estão distribuídos no espaço e definir as classes de distâncias geográficas (ou intervalo h), que serão utilizadas para estabelecer as diversas matrizes de conectividade $\mathrm{W}_{\mathrm{k}}$. E para cada uma dessas matrizes são calculados um I de Moran que formarão o correlograma espacial. Desta forma, as classes de distâncias são estabelecidas de forma irregular, de modo que as matrizes $\mathrm{W}_{\mathrm{k}}$ possuam aproximadamente o mesmo numero de conexões, tornando assim os índices I de Moran, que compõem o correlograma, comparáveis e com erros de estimativa semelhantes.

Os índices da distribuição espacial são apresentados por meio dos correlogramas plotados em função dos valores dos Índices de Moran e das classes de distância, para as seis espécies. O correlograma indica a extensão da estrutura espacial quando esta ocorre, e sua significância avaliada pelo Teste de Bonferroni, cujos valores de probabilidade se encontram nos correlogramas, respectivamente.

O programa SAAP 4.3 (Spatial Autocorrelation Analysis Program) foi utilizado para análises de autocorrelação espacial dos dados dos caráteres morfológicos (WARTENBERG, 1989) das espécies arbóreas que ocorreram em maior frequência nas áreas avaliadas.

\section{RESULTADOS E DISCUSSÃO}

A área objeto deste estudo apresentava como vegetação primária o Cerrado stricto sensu. Com a construção da Hidrelétrica houve intervenção de origem antrópica resultando na fragmentação da vegetação. O desmatamento provocou a diminuição do número de indivíduos arbóreos e consequentemente, da biodiversidade. Ainda que a hidroeletricidade, como alternativa para produção de energia, possa ser considerada ambientalmente mais vantajosa por utilizar recurso natural renovável e não poluente, a formação de reservatórios implica na ocorrência de diversos impactos ambientais (CESP, 1998).

A remoção do solo local culminou na perda da camada fértil do solo, do banco de sementes nativo e na modificação física, química e biológica do solo (fluxo e armazenamento de água; ciclagem de nutrientes e atividade microbiana, respectivamente). Ao longo dos anos, depois de cessada a antropização, iniciou-se o processo de regeneração natural e neste contexto, sob influência de fatores edáficos e da diversidade fitofisionômica serviram de base para discussão dos resultados deste trabalho.

A área a que cada parcela pertenceu, bem como seu número e coordenadas geográficas estão disponibilizados na Tabela 1 .

Cultura Agronômica, Ilha Solteira, v.24, n.4, p.301-320, 2015 
Tabela 1. Identificação das parcelas georeferenciadas, equidistantes aproximadamente 50 $\mathrm{m}$, posicionadas ao longo do transecto e classificadas em áreas distintas, conforme características do local, objeto deste trabalho, em área da FEPE-UNESP, município de Selvíria-MS.

\begin{tabular}{|c|c|c|c|c|c|}
\hline Área & Parcelas & Coordenadas & Área & Parcelas & Coordenadas \\
\hline \multirow{29}{*}{1} & P 1 & $0457806 \mathrm{~m} ; 7748201 \mathrm{~m}$ & \multirow[t]{2}{*}{2} & P 33 & $0457356 \mathrm{~m} ; 7746254 \mathrm{~m}$ \\
\hline & P 2 & $0457721 \mathrm{~m} ; 7748179 \mathrm{~m}$ & & P 34 & $0457355 \mathrm{~m} ; 7746176 \mathrm{~m}$ \\
\hline & P 3 & $0457642 \mathrm{~m} ; 7748131 \mathrm{~m}$ & \multirow{15}{*}{3} & P 35 & $0457344 \mathrm{~m} ; 7746098 \mathrm{~m}$ \\
\hline & P 4 & $0457564 \mathrm{~m} ; 7748134 \mathrm{~m}$ & & P 36 & $0457357 \mathrm{~m} ; 7746045 \mathrm{~m}$ \\
\hline & P 5 & $0457492 \mathrm{~m} ; 7748125 \mathrm{~m}$ & & P 37 & $0457365 \mathrm{~m} ; 7745988 \mathrm{~m}$ \\
\hline & P 6 & $0457431 \mathrm{~m} ; 7748077 \mathrm{~m}$ & & P 38 & $0457348 \mathrm{~m} ; 7745945 \mathrm{~m}$ \\
\hline & P 7 & $0457401 \mathrm{~m} ; 7748004 \mathrm{~m}$ & & P 39 & $0457371 \mathrm{~m} ; 7745914 \mathrm{~m}$ \\
\hline & P 8 & $0457375 \mathrm{~m} ; 7747928 \mathrm{~m}$ & & P 40 & $0457416 \mathrm{~m} ; 7745882 \mathrm{~m}$ \\
\hline & P 9 & $0457353 \mathrm{~m} ; 7747867 \mathrm{~m}$ & & P 41 & $0457436 \mathrm{~m} ; 7745828 \mathrm{~m}$ \\
\hline & P 10 & $0457342 \mathrm{~m} ; 7747804 \mathrm{~m}$ & & $\mathrm{P} 42$ & $0457475 \mathrm{~m} ; 7745812 \mathrm{~m}$ \\
\hline & P 11 & $0457332 \mathrm{~m} ; 7747687 \mathrm{~m}$ & & P 43 & $0457490 \mathrm{~m} ; 7745756 \mathrm{~m}$ \\
\hline & P 12 & $0457302 \mathrm{~m} ; 7747618 \mathrm{~m}$ & & P 44 & $0457543 \mathrm{~m} ; 7745729 \mathrm{~m}$ \\
\hline & P 13 & $0457305 \mathrm{~m} ; 7747528 \mathrm{~m}$ & & P 45 & $0457585 \mathrm{~m} ; 7745707 \mathrm{~m}$ \\
\hline & P 14 & $0457286 \mathrm{~m} ; 7747457 \mathrm{~m}$ & & P 46 & $0457633 \mathrm{~m} ; 7745673 \mathrm{~m}$ \\
\hline & P 15 & $0457287 \mathrm{~m} ; 7747389 \mathrm{~m}$ & & P 47 & $0457701 \mathrm{~m} ; 7745649 \mathrm{~m}$ \\
\hline & P 16 & $0457244 \mathrm{~m} ; 7747302 \mathrm{~m}$ & & P 48 & $0457739 \mathrm{~m} ; 7745612 \mathrm{~m}$ \\
\hline & P 17 & $0457203 \mathrm{~m} ; 7747247 \mathrm{~m}$ & & $\mathrm{P} 49$ & $0457768 \mathrm{~m} ; 7745571 \mathrm{~m}$ \\
\hline & P 18 & $0457146 \mathrm{~m} ; 7747214 \mathrm{~m}$ & & P 50 & $0457803 \mathrm{~m} ; 7745527 \mathrm{~m}$ \\
\hline & P 19 & $0457102 \mathrm{~m} ; 7747174 \mathrm{~m}$ & & P 51 & $0457827 \mathrm{~m} ; 7745453 \mathrm{~m}$ \\
\hline & P 20 & $0457024 \mathrm{~m} ; 7747188 \mathrm{~m}$ & 4 & P 52 & $0457867 \mathrm{~m} ; 7745425 \mathrm{~m}$ \\
\hline & P 21 & $0457440 \mathrm{~m} ; 7747039 \mathrm{~m}$ & 4 & P 53 & $0457913 \mathrm{~m} ; 7745399 \mathrm{~m}$ \\
\hline & P 22 & $0457432 \mathrm{~m} ; 7746971 \mathrm{~m}$ & & P 54 & $0457986 \mathrm{~m} ; 7745392 \mathrm{~m}$ \\
\hline & P 23 & $0457411 \mathrm{~m} ; 7746900 \mathrm{~m}$ & & P 55 & $0457949 \mathrm{~m} ; 7745346 \mathrm{~m}$ \\
\hline & P 24 & $0457403 \mathrm{~m} ; 7746830 \mathrm{~m}$ & & P 56 & $0457861 \mathrm{~m} ; 7748392 \mathrm{~m}$ \\
\hline & P 25 & $0457376 \mathrm{~m} ; 7746726 \mathrm{~m}$ & & P 57 & $0457896 \mathrm{~m} ; 7748464 \mathrm{~m}$ \\
\hline & P 26 & $0457424 \mathrm{~m} ; 7746728 \mathrm{~m}$ & & P 58 & $0457898 \mathrm{~m} ; 7748517 \mathrm{~m}$ \\
\hline & P 27 & $0457418 \mathrm{~m} ; 7746668 \mathrm{~m}$ & & P 59 & $0457916 \mathrm{~m} ; 7748553 \mathrm{~m}$ \\
\hline & P 28 & $0457374 \mathrm{~m} ; 7746641 \mathrm{~m}$ & 5 & P 60 & $0457930 \mathrm{~m} ; 7748644 \mathrm{~m}$ \\
\hline & P 29 & $0457340 \mathrm{~m} ; 7746586 \mathrm{~m}$ & & P 61 & $0457983 \mathrm{~m} ; 7748710 \mathrm{~m}$ \\
\hline & P 30 & $0457308 \mathrm{~m} ; 7746513 \mathrm{~m}$ & & P 62 & $0458004 \mathrm{~m} ; 7748789 \mathrm{~m}$ \\
\hline 2 & P 31 & $0457282 \mathrm{~m} ; 7746384 \mathrm{~m}$ & & P 63 & $0458038 \mathrm{~m} ; 7748889 \mathrm{~m}$ \\
\hline & P 32 & $0457309 \mathrm{~m} ; 7746311 \mathrm{~m}$ & & P 64 & $0458058 \mathrm{~m} ; 7748931 \mathrm{~m}$ \\
\hline
\end{tabular}

Obs.: P = parcela. Sistema de Coordenada Projetada em UTM, Fuso 22 Sul e DATUM SAD69.Áreas: 1: Área altamente antropizada (AAA); 2: Área medianamente antropizada (AMA); 3: Área pouco antropizada (APA); 4: Mata ciliar; 5: Reserva legal (RL).

\section{1 Índice de Moran}

O programa SAAP, utilizado para gerar as análises de autocorrelação espacial, serviuse de informações do georeferenciamento (coordenadas geográficas) e dos caráteres de crescimento como altura e diâmetro a altura do peito dos indivíduos arbóreos (Astronium fraxinifolium (gonçalo alves), Terminalia argentea (capitão do campo), Curatella americana (lixeira), Cupania vernalis (camboatá), Qualea jundiahy (pau terra de folha larga) e Andira cuyabensis (calunga), encontrados em quatro das cinco áreas avaliadas.

Dos 60 Índices de Moran, ou seja, dois caráteres de crescimento de seis espécies em 
cinco classes de distâncias, oriundos da análise de autocorrelação espacial, nove foram significativos ao nível de $5 \%$ de probabilidade. O correlograma da espécie Andira cuyabensis foi o único significativo para o caráter DAP.

De maneira geral, os índices de Moran situaram-se próximos a zero ao longo das classes de distâncias, com algumas exceções (Tabela 2). Ora pouco positivos, ora pouco negativos, porém, as espécies demonstraram baixa autocorrelação espacial para os caráteres analisados.

Neste caso, a polinização e a dispersão não devem ter tido um alcance muito grande, o que explica a elevada diferenciação entre os indivíduos nas diferentes classes de distâncias. Isso, por sua vez, pode estar relacionado a ação antrópica, já que as áreas estudadas encontram-se fragmentadas, não havendo corredores ecológicos o que contribuiria para o processo de dispersão.

Avaliando a diversidade genética, taxa de cruzamento e estrutura espacial de uma população de Cedrela fissilis, Gandara (1996) não encontrou autocorrelação espacial para os parâmetros genéticos avaliados. Segundo o autor, o fluxo gênico é fundamental na promoção da estruturação espacial. Fato este, que justifica os achados do presente trabalho, que a estruturação deva se encontrar numa distância maior que a abrangida pela amostragem, associado ao efeito ambiental.

O Índice de Moran, quando analisada a diversidade genética por isoenzimas em populações naturais de aroeira (Myracrodruon urundeuva), não apresentou autocorrelação espacial, o que sugere, distribuição aleatória dos genótipos. Entretanto, a ausência de estruturação espacial não descarta a existência de indivíduos aparentados (LACERDA, 1997).

Além do fluxo gênico, a dispersão restrita de sementes e a propagação vegetativa são fatores que interferem diretamente na estruturação.

Tabela 2. Valores médios de diâmetro a altura do peito (DAP) (cm), altura (ALT) (m) e Índice de Moran para DAP e ALT, referente às cinco classes de distância dos indivíduos das seis espécies avaliadas na FEPE-UNESP, município de Selvíria-MS.

\begin{tabular}{lcccc}
\hline \multirow{2}{*}{ Espécie avaliada } & \multicolumn{2}{c}{ Valores médios } & \multicolumn{2}{c}{ Índice de Moran } \\
\cline { 2 - 5 } & DAP $(\mathbf{c m})$ & ALT $(\mathbf{m})$ & DAP & ALT \\
\hline Andira cuyabensis & 13,68 & 5,97 & $0,84^{* *}(1)$ & n.s. \\
Qualea jundiahy & 11,75 & 6,09 & $0,66^{*}(4)$ & \\
& & & $-0,24^{*}(1)$ & n.s. \\
Terminalia argentea & 11,32 & 8,15 & $-0,43^{*}(4)$ & n.s. \\
Cupania vernalis & 11,82 & 8,20 & n.s. & $0,29^{*}(1)$ \\
& & & & $-0,51^{*}(3)$ \\
Curatella americana & 13,38 & 5,42 & n.s. & $-0,54^{*}(4)$ \\
Astronium fraxinifolium & 10,04 & 8,98 & n.s. & n.s. \\
\hline
\end{tabular}

Cultura Agronômica, Ilha Solteira, v.24, n.4, p.301-320, 2015 
Segundo Diniz-Filho (1998), correlogramas não significativos pelo Teste de Bonferroni, indicam que as variabilidades entre os caráteres morfológicos estudados estão distribuídas aleatoriamente sobre o espaço, ou seja, não existe padrão espacial.

A existência de um padrão espacial dos caráteres de crescimento é importante para a compreensão de como se dá a ocorrência natural dos indivíduos destas espécies.

\subsubsection{Interpretação dos resultados obtidos do Índice de Moran}

As espécies Andira cuyabensis, Qualea jundiahy e Terminalia argentea apresentaram valores significativos para caráter DAP. A Cupania vernalis e Curatella americana apresentaram significância para altura, contudo, o Astronium fraxinifolium não apresentou significância em nenhuma classe de distância.

O correlograma da Andira cuyabensis apresentou estruturação populacional para o caráter DAP, significativa ao nível de 5\% de probabilidade, aos indivíduos avaliados na classe de distância um (correlograma significativo). Os indivíduos situados nesta classe de distância foram semelhantes em relação a este caráter. Já na classe 4, o índice foi significativo, porém negativo, não havendo semelhança entre os indivíduos em relação ao DAP.

Portanto, os indivíduos encontrados em distâncias dentro da classe um, tendem a ser similares para o DAP, sendo que esta semelhança decai com o aumento da distância até que subpopulações situadas a mais de $2500 \mathrm{~m}$ sejam completamente diferentes para este caráter. Comportamento análogo foi verificado por Telles et al. (2001) quando estudaram a autocorrelação espacial das frequências alélicas em subpopulações de cagaiteira no sudeste de Goiás. Desta forma, pode-se inferir que é viável o uso das sementes, oriundas dos indivíduos da classe um em programas de melhoramento, quando o interesse seja o caráter DAP, pois a altura não apresentou estruturação significativa.

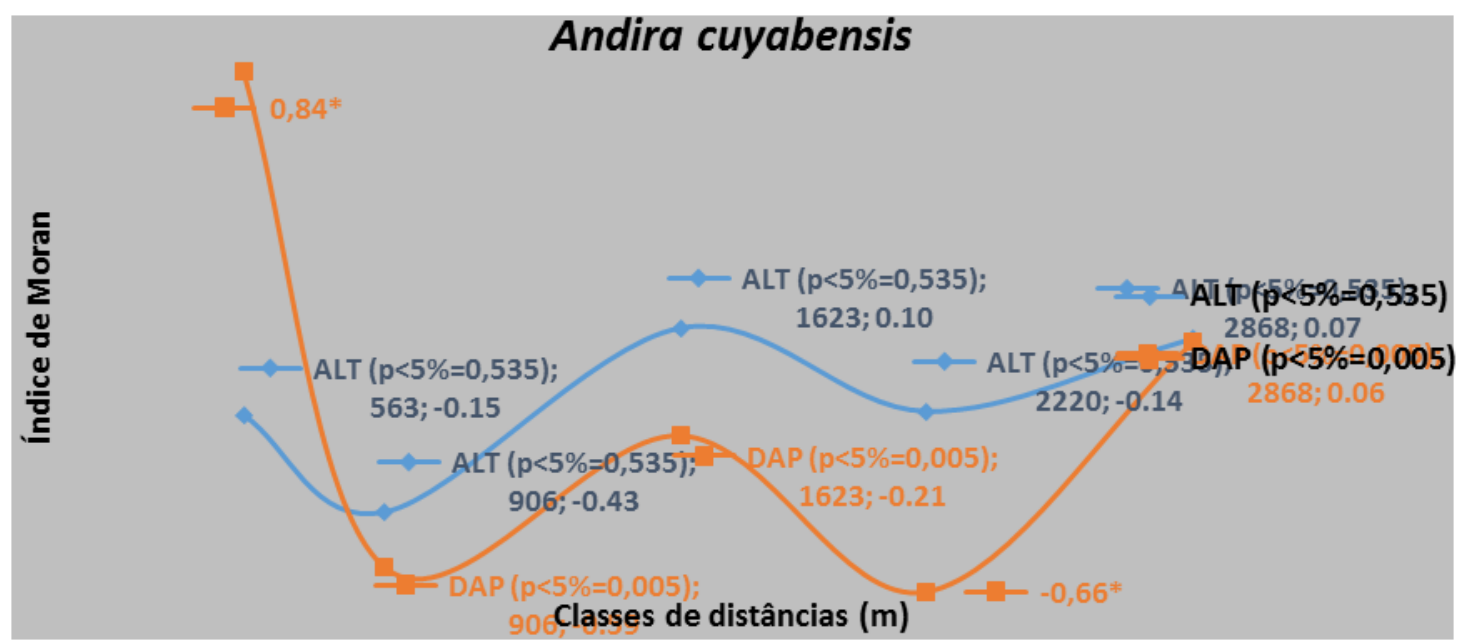

Figura 1. Correlograma espacial dos Índices de Moran para as cinco classes de distâncias entre os indivíduos de uma população de Andira cuyabensis, em área da FEPE-UNESP, município de Selvíria-MS.

Cultura Agronômica, Ilha Solteira, v.24, n.4, p.301-320, 2015 
O correlograma da espécie Qualea jundiahy apresentou estruturação para DAP nas classes de distâncias um e dois, positiva e negativa, respectivamente; e o correlograma da espécie Terminalia argentea apresentou estruturação na classe quatro (negativa), para o mesmo caráter, entretanto, em nenhuma houve significância para o teste de Bonferroni.

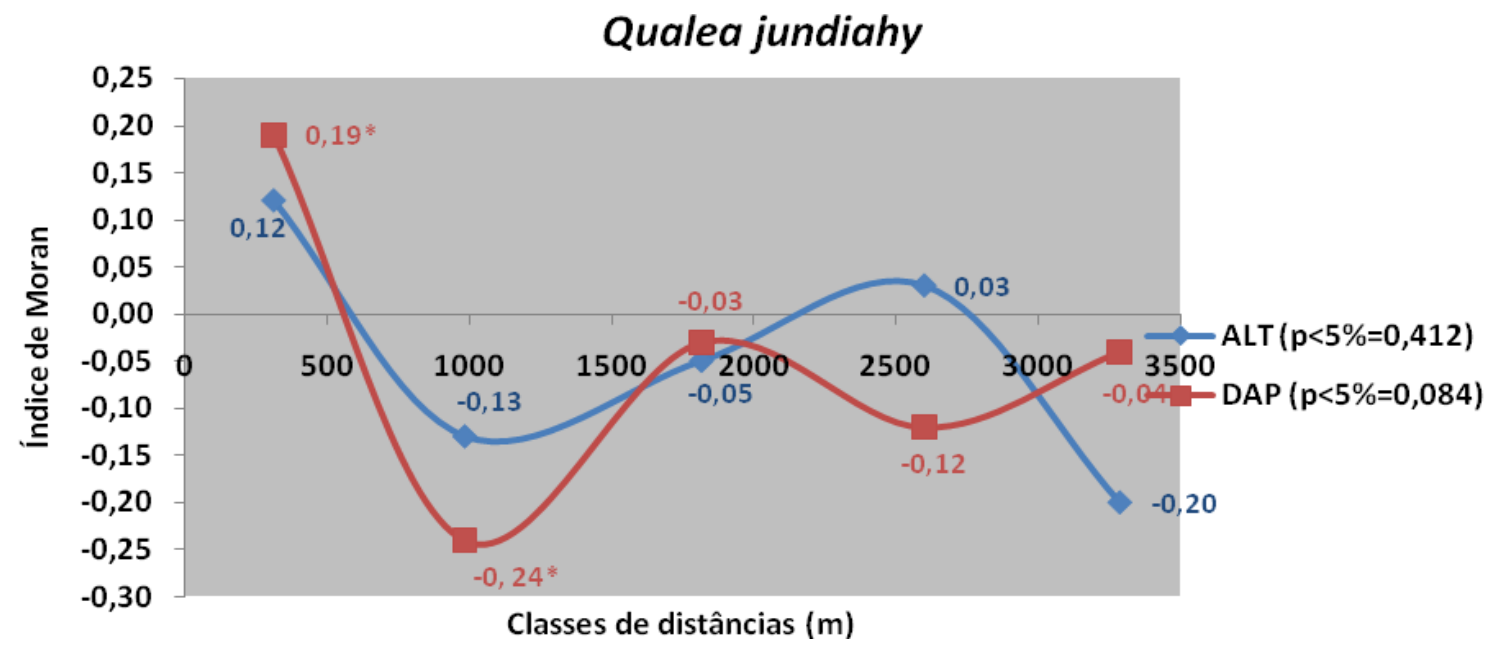

Figura 2. Correlograma espacial dos Índices de Moran para as cinco classes de distâncias entre os indivíduos de uma população de Qualea jundiahy, em área da FEPE-UNESP, município de Selvíria-MS.

O correlograma da espécie Cupania vernalis apresentou valores significativos para altura nas classes de distâncias um, três e quatro. Na classe um foi positiva indicando maior semelhança, já nas classes três e quatro, indicou menor semelhança para o caráter altura.

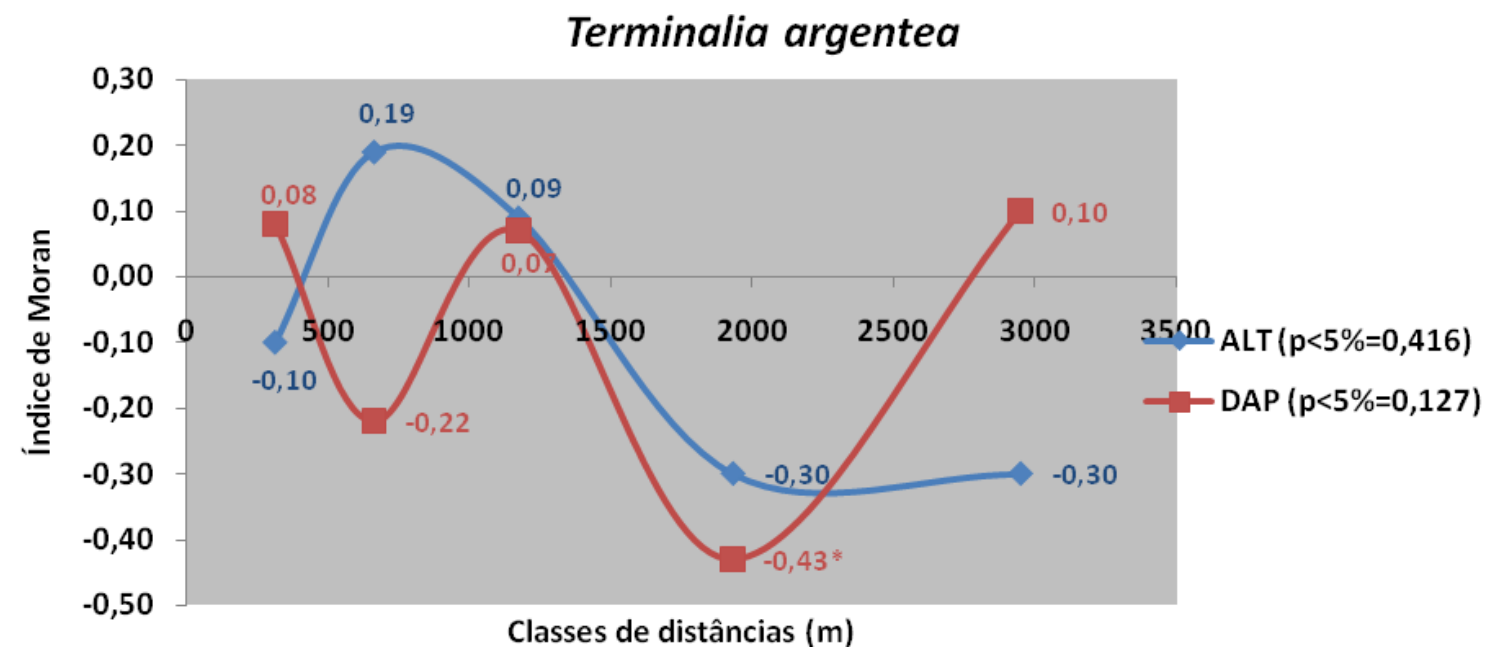

Figura 3. Correlograma espacial dos Índices de Moran para as cinco classes de distâncias entre os indivíduos de uma população de Terminalia argentea, em área da FEPE-UNESP, município de Selvíria-MS.

Cultura Agronômica, Ilha Solteira, v.24, n.4, p.301-320, 2015 


\section{Cupania vernalis}

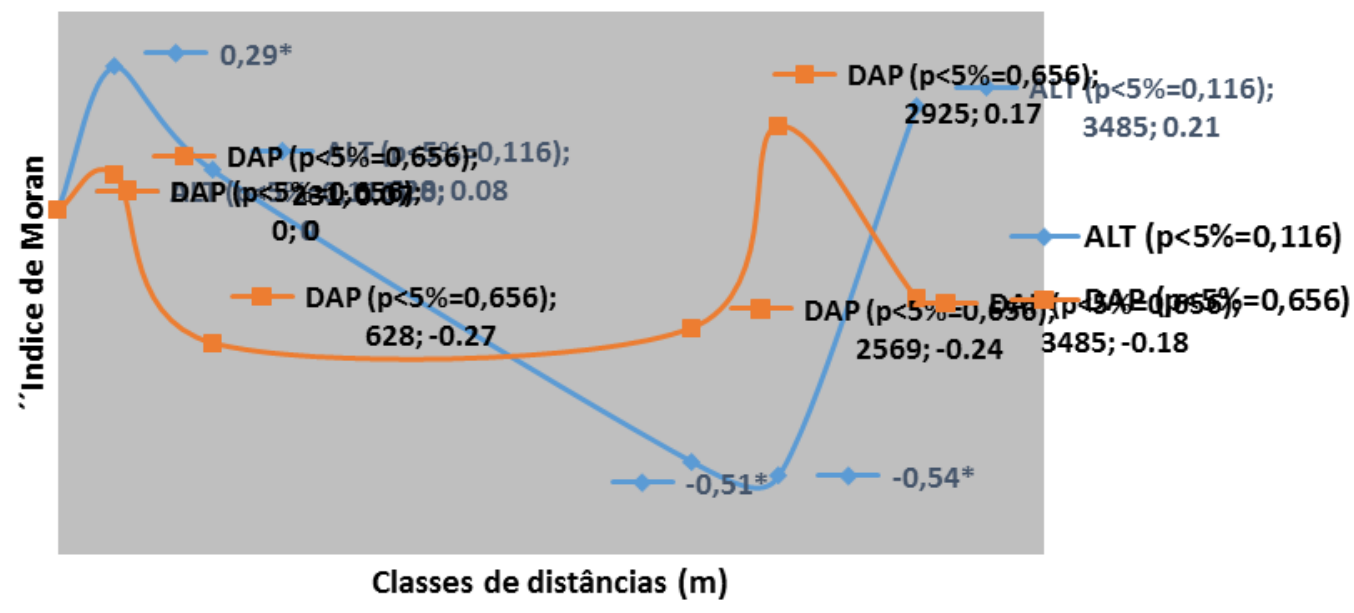

Figura 4. Correlograma espacial dos Índices de Moran para as cinco classes de distâncias entre os indivíduos de uma população de Cupania vernalis, em área da FEPE-UNESP, município de Selvíria-MS.

O correlograma da espécie Curatella americana apresentou significância apenas para altura na classe dois, sinalizando pouca estruturação para este caráter. A população deve ter sido originada de poucos indivíduos, uma vez que, a população de ocorrência natural para esta espécie é de uma planta por hectare, segundo Silva Junior et al. (2005). Como grande parte da área foi antropizada, pode ter ocorrido uma perturbação na dinâmica populacional desta espécie e com isso, pode-se designá-la como pioneira antrópica. Esta espécie é influenciada pelos indivíduos que estão no entorno, por isso, da significância para o caráter altura.

\section{Curatella americana}

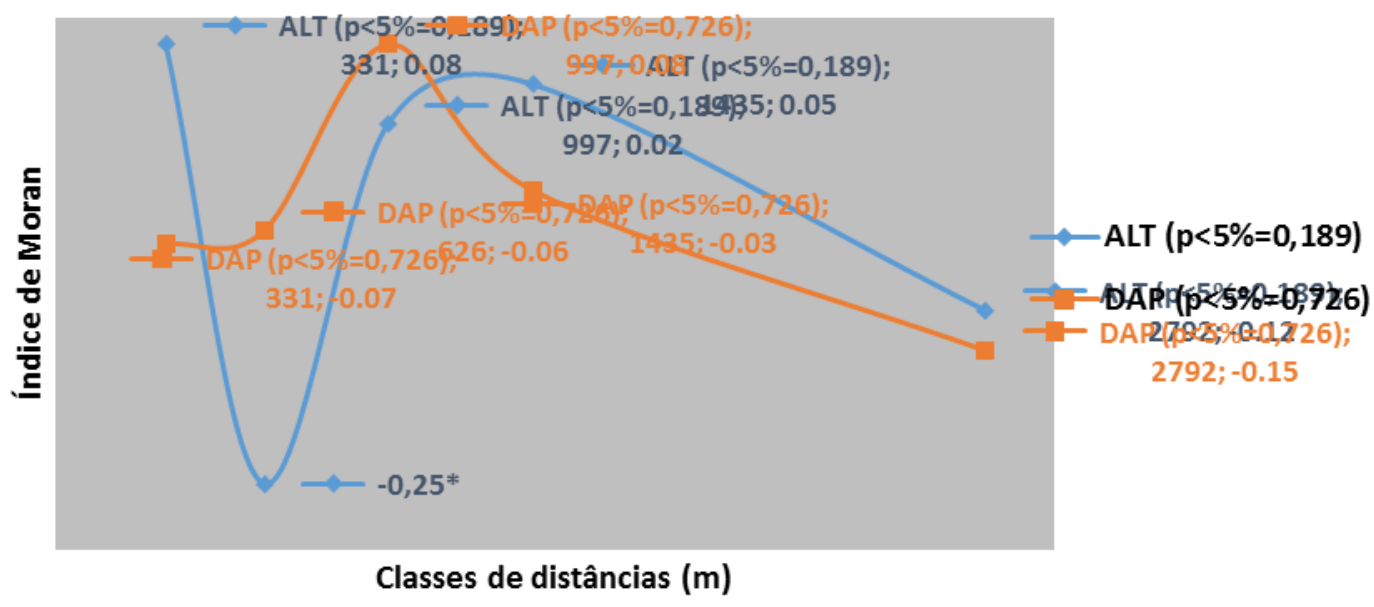

Figura 5. Correlograma espacial dos Índices de Moran para as cinco classes de distâncias entre os indivíduos de uma população de Curatella americana, em área da FEPE-UNESP, município de Selvíria-MS.

O correlograma da espécie Astronium fraxinifolium apresentou uma distribuição 
aleatória de indivíduos, sem estruturação e baixa correlação, uma vez que, os valores são próximos a zero e não significativos.

Em um estudo de autocorrelação espacial de caráteres morfológicos em populações naturais de Astronium fraxinifolium, Aguiar et al. (2004) encontraram valores não significativos e próximos a zero, semelhantemente aos do presente trabalho. Analogamente, Silva et al. (2005), avaliando a autocorrelação espacial em população natural de Caryocar brasiliense não encontraram padrão espacial para os caráteres de crescimento avaliados.

Os dados de autocorrelação espacial do presente trabalho poderão servir de comparativo para futuras pesquisas no intuito de verificar o efeito da fragmentação do hábitat gerada por ação antrópica, independentemente do padrão de distribuição espacial.

Sobre indicadores de sustentabilidade de florestas naturais, uma espécie mantém sua evolução normal caso não incida ações antrópicas; além do que, a taxa de crescimento e o Índice de Moran servem de parâmetros para monitorarem as interações da espécie com outros organismos (GANDARA et al., 1997 citados por GANDARA; KAGEYAMA 1998).

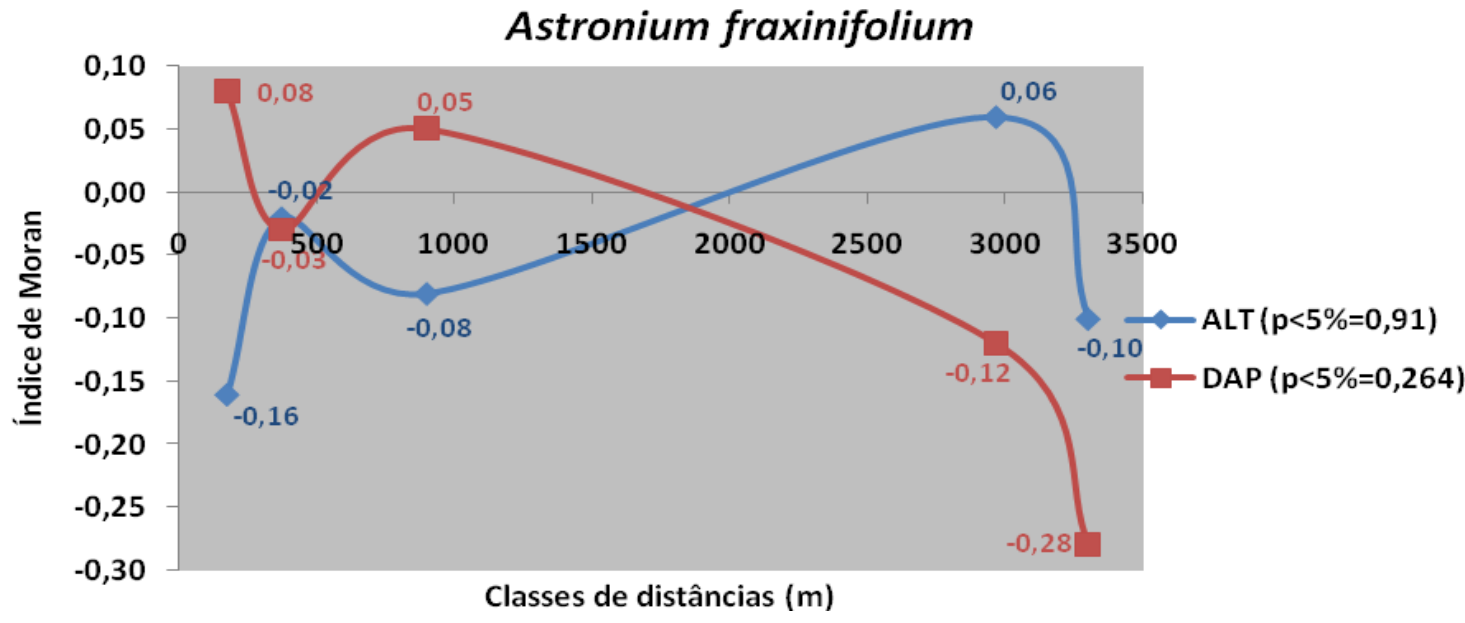

Figura 6. Correlograma espacial dos Índices de Moran para as cinco classes de distâncias entre os indivíduos de uma população de Astronium fraxinifolium, em área da FEPEUNESP, município de Selvíria-MS.

O reconhecimento dos padrões de distribuição espacial é importante, pois fornecem subsídios para programas de conservação genética in situ, manejo, domesticação e melhoramento genético de espécies arbóreas. Rodrigues (2010), estudando a variação genética para caráteres silviculturais em banco ativo de germoplasma de espécies arbóreas, constatou alto desempenho para o Astronium fraxinifolium no tocante a sobrevivência, e ainda relata que esta avaliação traz informações importantes em relação ao controle genético deste caráter no que se refere à adaptação das progênies em condição de cultivo ex situ.

Das seis espécies mais frequentes, identificadas neste trabalho, pode-se inferir que, a Astronium fraxinifolium (Figura 6), provavelmente, possui uma base genética mais ampla que as demais, sendo recomendada a coleta de sementes para programas de conservação genética in situ ou ex situ; podendo ser realizada em qualquer classe de distância que mesmo

Cultura Agronômica, Ilha Solteira, v.24, n.4, p.301-320, 2015 
assim, garante variabilidade.

Das 97 espécies encontradas, seis têm potencial para serem utilizadas num programa de conservação genética in situ. São elas: Astronium fraxinifolium, Terminalia argentea, Curatella americana, Cupania vernalis, Qualea jundiahy e Andira cuyabensis. Com base na distribuição espacial a espécie mais indicada é Astronium fraxinifolium por não apresentar estruturação em nenhuma das classes de distâncias.

\section{CONCLUSÃO}

a) A altura, DAP e Forma foram indicadores eficazes para avaliar o crescimento da comunidade arbórea local;

b) Na Mata ciliar os valores de altura e forma foram superiores;

c) Das 97 espécies encontradas, seis têm potencial para serem utilizadas num programa de conservação genética in situ, sendo: Astronium fraxinifolium, Terminalia argentea, Curatella americana, Cupania vernalis, Qualea jundiahy e Andira cuyabensis. Sendo a espécie, Astronium fraxinifolium, a mais indicada.

\section{REFERÊNCIAS BIBLIOGRÁFICAS}

AGUIAR, A. V.; COELHO, A. S. G.; MOURA, M. F.; MORAIS, L. K.; PINHEIRO, J. B.; MORAES, M. L. T.; ZUCCHI, M. I.; MOURA, N. F.; VENCOVSKY, R. Autocorrelação espacial de caracteres morfológicos em populações naturais de gonçalo-alves (Astronium fraxinifolium Schott). Bioscience of Journal, Uberlândia, v. 20, n. 1, p.151-160, 2004.

ALMEIDA, S. P.; PROENÇA, C. E. B.; SANO, S. M.; RIBEIRO, J. F. Cerrado espécies vegetais úteis. Planaltina: Embrapa/CPAC, 1998. 464 p.

ALVES, M. C.; SOUZA, Z. M. Recuperação de área degradada por construção de hidroelétrica com adubação verde e corretivo. Revista Brasileira de Ciência do Solo, Viçosa, v. 32, n. 6, p.2505-2516, 2008.

ARAGÃO, S. F. Conservação genética in situ de espécies arbóreas que ocorrem na transição da floresta estacional semidecidual e o Cerrado em Selvíria - MS. 2008. 131 f. Dissertação (Mestrado em Agronomia - Sistemas de Produção) - Faculdade de Engenharia de Ilha Solteira, Universidade Estadual Paulista, Ilha Solteira, 2008.

BARBOSA, L. M.; BARBOSA, T. C.; BARBOSA, K. C.; PARAJARA, F. C. Recuperação de Matas Ciliares do Estado de São Paulo: Avanços e Perspectivas para Conservação Ambiental. In: BARBOSA, L.M. II Curso de Capacitação em Recuperação Áreas Degradadas com Ênfase em Matas Ciliares. Mogi Gaçu: Instituto de Botânica Faculdade Municipal Prof. Franco Montoro, 2008. 80 p.

Cultura Agronômica, Ilha Solteira, v.24, n.4, p.301-320, 2015 
CARVALHO, P. E. R. Espécies arbóreas brasileiras. Colombo: Embrapa-CNPF, 2006. v. $2,627 \mathrm{p}$.

COMPANHIA ENERGÉTICA DO ESTADO DE SÃO PAULO - CESP. Diretoria do Meio Ambiente. Recomposição vegetal. São Paulo: CESP, 1998. 11 p.

DEMATTÊ, J. L. I. Levantamento detalhado dos solos do "Campus experimental de Ilha Solteira". Piracicaba: USP/ESALQ, 1980. 119 p.

DINIZ-FILHO, J. A. F. Análise de autocorrelação espacial: inferências microevolutivas e aplicações em genética de populações. Ribeirão Preto: Sociedade Brasileira de genética, 1998. n. 6, p. 82-145. (Série monografias)

DURIGAN, G.; BAITEllo, J. B.; FRANCO, G. A. D. C.; SIQUEIRA, M. F. Plantas do cerrado paulista: imagens de uma paisagem ameaçada. São Paulo: Páginas \& Letras, 2004. $475 \mathrm{p}$.

EMPRESA BRASILEIRA DE PESQUISA AGROPECUÁRIA - EMBRAPA. Sistema Brasileiro de Classificação de Solos. 2. ed. Rio de Janeiro: Centro Nacional de Pesquisa de Solos, 2006. 306 p.

GANDARA, F. B. Diversidade genética, taxa de cruzamento e estrutura espacial dos genótipos em uma população de Cedrela fissilis Vell. (Meliaceae). 1996. 69 f. Dissertação (Mestrado em Ciências) - Universidade Estadual de Campinas, Campinas, 1996.

GANDARA, F. B.; KAGEYAMA, P. Y. Indicadores de sustentabilidade de florestas naturais. Série Técnica IPEF, Piracicaba, v. 12, n. 31, p.79-84, 1998.

GUERRA, C. R. S. B. Conservação genética ex situ de populações naturais de Myracrodruon urundeuva fr. all. em sistema silvipastoril. 2008. 108 f. Tese (Doutorado em Agronomia - Sistemas de Produção) - Faculdade de Engenharia de Ilha Solteira, Universidade Estadual Paulista, Ilha Solteira, 2008.

HAYAWARD, M. D.; HAMILTON, N. R. S. Genetic diversity: population structure and conservation. In: CALLOW, J. A.; FORD-LLOYD, B. V.; NEWBURY, H. J. Biotechnology and plant genetic resources: conservation and use. Wallingford: CABI, 1997. p. 49-76. (Biotechnology in Agriculture Series, 19)

KAGEYAMA, P. Y. Reflexos e potenciais da resolução SMA-21 de 21/11/2001 na conservação da biodiversidade específica e genética. In: SEMINÁRIO TEMÁTICO SOBRE RECUPERAÇÃO DE ÁREAS DEGRADADAS, 2003, São Paulo. Anais... São Paulo: [s.n.], 2003. p. 7-12.

Cultura Agronômica, Ilha Solteira, v.24, n.4, p.301-320, 2015 
KAGEYAMA, P. Y.; GANDARA, F. B. Dinâmica de populações de espécies arbóreas: implicações para o manejo e a conservação. In: SIMPÓSIO DE ECOSSISTEMAS DA COSTA BRASILEIRA, 3., 1993, Serra Negra. Simpósio... São Paulo: ACIESP, 1993. v. 2, p. $1-9$.

KOPPEN, W. Climatologia. México: Fondo de Cultura Econômica, 1948. 496 p.

LACERDA, C. M. B. Diversidade genética por isoenzimas em populações naturais de aroeira (Myracrodruon urundeuva Freire, F. \& M. F. Allemão). 1997. 96 f. Dissertação (Mestrado em Genética e Melhoramento de Plantas) - Escola Superior de Agricultura "Luiz de Queiroz”, Universidade de São Paulo, Piracicaba, 1997.

LORENZI, H. Árvores brasileiras: manual de identificação e cultivo de plantas arbóreas nativas do Brasil. 4. ed. Nova Odessa: Plantarum, 2002. v. 1. 368 p. (a)

LORENZI, H. Árvores brasileiras: manual de identificação e cultivo de plantas arbóreas nativas do Brasil. 2. ed. Nova Odessa: Plantarum, 2002. v. 2. 368 p. (b)

MORAN, P. A. F. Notes on continuous stochastic phenomena. Biometrika, London, v. 37, n. $1 / 2$, p.17-23, 1950 .

MYERS, N.; MITTERMEIER, R. A.; MITTERMEIER, C. G.; FONSECA, G. A. B.; KENT, J. Biodiversity hotspots for conservation priorities. Nature, London, v. 403, n. 1, p.853-858, 2000.

NASCIMENTO, H. E. M.; DIAS, A. S.; TABANEZ, A. A. J.; VIANA, V. M. Estrutura e dinâmica de populações arbóreas de um fragmento de floresta estacional semidecidual na região de Piracicaba, SP. Revista Brasileira de Biologia, São Carlos, v. 59, n. 2, p.329342, 1999.

RAMOS, V. S.; DURIGAN, G.; FRANCO, G. A. D. C.; SIQUEIRA, M. F.; RODRIGUES, R. R. Árvores da floresta estacional semidecidual: guia de identificação de espécies. São Paulo: EdUSP Biota/FAPESP, 2008. 312 p.

REIS, A.; BECHARA, F. C.; ESPINDOLA, M. B.; VIERA, N. K.; SOUZA, L. L. Restauração de áreas degradadas: a nucleação como base para incrementar os processos sucessionais. Natureza e Conservação, Curitiba, v. 1, n. 1, p.28-36, 2003.

RODRIGUES, C. J. Variação genética para caracteres silviculturais em banco ativo de germoplasma de espécies arbóreas do cerrado e da floresta estacional semidecidual. 2010. 187 f. Tese (Doutorado em Agronomia - Sistemas de Produção) - Universidade Estadual Paulista, Ilha Solteira, 2010.

Cultura Agronômica, Ilha Solteira, v.24, n.4, p.301-320, 2015 
RODRIGUES, G. B.; MALTONI, K. L.; CASSIOLATO, A. M. R. Dinâmica da regeneração do subsolo de áreas degradadas dentro do bioma Cerrado. Revista Brasileira de Engenharia Agrícola Ambiental, Campina Grande, v. 11, n. 1, p.73-80, 2007.

SILVA JUNIOR, M. C.; NOGUEIRA, P. E.; MUNHOS, C. B. R.; RAMOS, A. E. 100 árvores do Cerrado. Brasília: Rede sementes do Cerrado, 2005. 278 p.

SILVA, A. M.; CANUTO, D. S. O.; AGUIAR, A. V.; MORAES, M. K. T. Autocorrelação espacial em uma população natural de piqui (Caryocar brasiliense Camb.) em área degradada. In: ENCONTRO DE GEÓGRAFOS DA AMÉRICA LATINA, 10, 2005, São Paulo. Anais... São Paulo: Universidade de São Paulo, 2005. p. 14233-14243.

SIMON, M. F. Manual de curadores de germoplasma - Vegetal: Conservação in situ. 2010, Brasília: EMBRAPA, 2010. 14 p. (Documentos 322).

SOKAL, R. R.; ODEN, N. L. Spatial autocorrelation in biology. 1: metodology. Biological Journal of the Linnean Society, London, v. 10, p.199-228, 1978a.

SOKAL, R. R.; ODEN, N. L. Spatial autocorrelation in biology. 2: some biological implications and four applications of evolutionary and ecological interest. Biological Journal of the Linnean Society, London, v. 10, p.229-249, 1978b.

SOUZA, V. C.; LORENZI, H. Botânica sistemática: guia ilustrado para identificação das famílias de Angiospermas da flora brasileira, baseado em APG II. Nova Odessa: Instituto Plantarum, 2005. 640 p.

TElleS, M. P. C.; DINIZ-FIlHO, J. A. F.; COElHO, A. S. G.; CHAVES, L. J. Autocorrelação espacial das frequências alélicas em subpopulações de cagaiteira (Eugenia dysenterica DC., Myrtaceae) no sudeste de Goiás. Revista Brasileira de Botânica, São Paulo, v. 24, n. 2, p.145-154, 2001.

UNIVERSIDADE ESTADUAL PAULISTA - UNESP. Departamento de Fitossanidade, Engenharia Rural e Solos/Área de Hidráulica e Irrigação. Dados climáticos de Ilha Solteira. Ilha Solteira, 2010. Disponível em: http://www.agr.feis.unesp.br/ilhadados.php. Acesso em: 13 jul. 2010.

WARTENBERG, D. SAAP: Spatial autocorrelation analysis program. New York: Exerter, 1989. 01 CR-ROM.

Cultura Agronômica, Ilha Solteira, v.24, n.4, p.301-320, 2015 
